\title{
Dinámica relacional de la gestión turística en el pueblo mágico de Calvillo, Aguascalientes, México
}

\author{
Astrid Vargas Vázquez \\ Ismael M. Rodríguez Herrera \\ Departamento de Turismo \\ Universidad Autónoma de Aguascalientes
}

\section{Resumen}

Este estudio, de tipo descriptivo, cualitativo y transeccional, buscó probar el supuesto de que los actores de Calvillo tenían una escasa colaboración para la gestión turística. Para ello se diseñó un instrumento que permitiera conocer las relaciones de los principales actores de la localidad. El análisis de los resultados se realizó a través de Ucinet 6 y NetDraw 9.091 generando los estadísticos correspondientes y sociogramas. Los resultados muestran una red integrada amplia pero poco cohesionada, donde los actores representantes de turismo municipal y estatal, así como el Consejo, figuran como los que tienen legitimidad y poder. Sin embargo, el presidente del Comité Pueblos Mágicos quien debería tener a su cargo la gestión principal sólo tiene legitimidad y urgencia. Ello lleva a reflexionar sobre la importancia de fortalecer las relaciones entre actores, pues a pesar de los esfuerzos de asociacionismo, no hay colaboración entre el sector público y privado que permita a Calvillo posicionarse como un destino exitoso.

\section{Palabras clave}

Análisis de redes, gestión de destinos, pueblos mágicos, partes interesadas, desarrollo local. 


\title{
Relational dynamics of tourism management in the magical village (Pueblo Mágico) of Calvillo, Aguascalientes, Mexico
}

\author{
Astrid Vargas Vázquez \\ Ismael M. Rodríguez Herrera \\ Departamento de Turismo \\ Universidad Autónoma de Aguascalientes
}

\begin{abstract}
Abstrac
The descriptive, qualitative and cross-sectioned study tried to prove the hypothesis that actors in Calvillo showed a limited cooperation for tourism management. For that reason an instrument was designed to know the relationships among the locality main actors. The analysis of the results was made using UCINET 6 and NetDraw 9.091 to generate the pertinent statistics and sociograms. The results show a wide integrated network, but little cohesive, where the locality and the state tourism representatives as well as the Council represent legitimacy and power. However, the president of the magical towns committee, who should be in charge of the main management, only has legitimacy and urgency. This situation brings to a reflection about the importance of strengthening the relationship among the actors because despite the association efforts, there is no cooperation between the public and private sectors that could allow Calvillo to be placed as a successful destination.
\end{abstract}

\section{KEY WORDS}

Networks analysis, destinations management, magical towns, interested parts, local development. 


\section{Introducción}

Desde hace más de una década uno de los programas públicos de la Secretaría de Turismo Federal (Sectur) para implementar su política de promoción a la actividad turística en pequeñas localidades ha sido el denominado programa Pueblos Mágicos de México. Éste ha significando para la institución un estandarte en el impulso al desarrollo local de destinos emergentes y en la diversificación de productos turísticos a nivel nacional, al grado de que el modelo ha llamado la atención de varios países que han manifestado interés por replicarlo.

A pesar de lo anterior, algunos estudios como el desarrollado por Rodríguez y Pulido (2012) han demostrado que no todas las localidades integrantes del programa presentan el mismo nivel de desarrollo turístico, y que las características tanto de su oferta como de la demanda que los visita son muy distintas; incluso, su grado de organización civil es muy disímil. Esto último a pesar de los requerimientos indispensables que ha establecido el propio programa como es la conformación del denominado Comité Pueblos Mágicos (Sectur, 2009). Lo anterior, como es lógico, obedece a que cada una de las localidades integrantes del programa tiene un contexto singular, especialmente en el ámbito social, y ello puede implicar el éxito o fracaso como destino turístico, por lo que se considera debe ser un aspecto fundamental para tomarse en cuenta.

Si se analiza la lista de localidades del programa, destaca que en el año 2012 se integraron prácticamente la mitad de los 83 destinos que lo conforman, y entre ellos se encuentra la localidad de Calvillo, cabecera del municipio homónimo ubicado en el estado de Aguascalientes. Este municipio tenía ya una trayectoria en la gestión turística debido a su vocación para el desarrollo del denominado "turismo de naturaleza" y la recreación de los habitantes de la ciudad de Aguascalientes y la región, por ello, en los últimos diez años el crecimiento empresarial local del sector turístico-recreativo ha sido notable así como el fortalecimiento de la gestión municipal en el área turística. Es así que en el municipio de Calvillo se observan diversos actores interesados en la gestión turística de la localidad pero con poca colaboración entre ellos para lograr un objetivo común; por tanto, surgen diversas preguntas de investigación: ¿Quiénes 
intervienen en la gestión turística de Calvillo?, ¿qué influencia tiene cada uno de los actores? La declaratoria como Pueblo Mágico, igarantiza una dinámica relacional colaborativa entre actores gubernamentales y de la iniciativa privada para lograr un objetivo de desarrollo turístico común? ¿Es determinante el Comité Pueblo Mágico para las gestiones?

Ante tal problemática, se plantearon los siguientes objetivos de investigación: Identificar a los principales actores de la gestión turística del municipio de Calvillo; determinar el nivel de influencia de las partes interesadas (stakeholders) en la gestión turística del destino en cuestión; analizar la dinámica relacional entre los principales actores de la gestión turística de Calvillo para establecer la colaboración actual entre ellos.

Y se propuso como supuesto de este trabajo que: "Las partes interesadas del municipio de Calvillo, en el estado de Aguascalientes muestran una escasa relación entre ellos para colaborar en la gestión turística de su localidad, lo que no ha mejorado con la incorporación al programa Pueblos Mágicos”.

El análisis de redes sociales fue la herramienta de investigación con la cual se pretendió alcanzar los objetivos y probar el supuesto mencionado líneas arriba. Cabe señalar que el análisis de redes resulta útil para identificar claramente la dinámica social de personas, empresas, instituciones, comunidades, entre otros aspectos, en un territorio y espacio determinado. Su aplicación, por lo menos en el campo de las ciencias sociales, es muy vasta y tiene sus orígenes, según Freeman (2012), a partir de los años veinte del siglo pasado, logrando consolidarse como un campo científico reconocido en la década de los setenta. Freeman $(2012,3)$ indica que recientemente se han integrado cuatro estrategias a un paradigma organizado de investigación y que caracterizan el análisis de redes sociales, las cuales son:

1. El análisis de redes sociales parte de la intuición estructural de la existencia de lazos que ligan a actores sociales

2. Está basado en información empírica sistemática

3. Hace amplio uso de imágenes gráficas y

4. Utiliza modelos matemáticos o computacionales. 
Se debe hacer mención de que la aplicación de esta herramienta en el sector turístico todavía es incipiente a nivel mundial. Se ha utilizado para evaluar modelos de desarrollo turístico, gestión del desarrollo local, manejo de áreas naturales, entre otros campos relacionados (Merinero, 2009; Merinero y Pulido, 2009; Prell, Hubacek y Reed, 2007), destacando la importancia de los actores en la gestión turística como elemento indispensable para avanzar en el proceso del desarrollo sustentable.

En México, los estudios de este tipo han servido para probar algunas teorías, como la de las partes interesadas y capital social, así como modelos de turismo alternativo, turismo transfronterizo y gestión turística adaptativa principalmente (Vargas y Rodríguez, 2012; Cuevas, 2007; Cruz, 2008), todavía con una gran área de oportunidad para su aprovechamiento en la toma de decisiones.

Como ya se mencionó, el análisis de redes permite identificar stakeholders, actores, agentes o partes interesadas, ${ }^{1}$ los cuales son definidos por Freeman (1984) como "cualquier grupo o individuo que puede afectar, o es afectado por, la consecución del propósito de una corporación” (citado por Pulido Fernández, 2010, p. 150). Lo anterior permitió utilizar también el análisis de stakeholder, definido por Grimble, Chan, Aglionby y Quan (1995, p. 3) como:

Un enfoque para comprender un sistema, identificando a los actores clave o partes interesadas en el sistema, y la evaluación de sus respectivos intereses en ese sistema. Las partes interesadas incluyen a todos los que afecta, y / o se ven afectados por las políticas, decisiones y acciones del sistema; ya que pueden ser individuos, comunidades, grupos sociales o instituciones de cualquier tamaño, afiliación o nivel en la sociedad. El término incluye tanto a los responsables políticos, planificadores y administradores en las organizaciones gubernamentales y de otro tipo, así como los grupos de usuarios comerciales y de subsistencia.

Por su parte, autores como Mitchell, Agle y Wood (1997) mencionan en su obra que los actores están determinados por tres atributos que facilitan su identificación; establecen que el agente que posea los tres rasgos en un mismo tiempo y espacio es una parte interesada en el tema en cuestión. Cabe señalar

${ }^{1}$ Conceptos similares que para los fines de esta investigación serán tratados como sinónimos. 
que esta teoría está enfocada a organizaciones empresariales, sin embargo, la presente investigación la toma como referencia para caracterizar a la red del caso de estudio. Los atributos que menciona la teoría de las partes interesadas se refieren a que un actor puede tener influencia o poder, entendido como "una relación en medio de actores sociales en la cual un actor social A puede conseguir que otro actor social B, haga algo que B nunca haría de otra forma”; legitimidad, esto es, "una percepción generalizada o una hipótesis de que las acciones de una entidad son deseables, propias o apropiadas con algún sistema de normas, valores, beneficios y definiciones construido socialmente"; y, urgencia, entendida como "el grado para el cual el derecho del stakeholder demanda una atención inmediata” (Mitchell et al, 1997. p. 869).

\section{Marco contextual}

Como ya se indicó en la parte introductoria, el caso de estudio se centra en el municipio de Calvillo, el cual se localiza en el poniente del estado de Aguascalientes. Cuenta con una superficie de $931.26 \mathrm{~km}^{2}$, representando más de $16 \%$ del territorio estatal. La cabecera municipal se encuentra a una altitud de 1630 msnm y su orografía es variada, lo que da pie a que su clima sea cálido la mayor parte del año (Gobierno del Estado de Aguascalientes, 2008). Como consecuencia de lo anterior, la cobertura vegetal está compuesta por bosques de encino en las zonas altas de las áreas naturales protegidas como la Sierra Fría y la Sierra de Laurel, en las cañadas y zonas de transición se puede encontrar selva baja caducifolia y en el valle de Huejúcar se localizan grandes extensiones de cultivo de guayaba, principal producto agropecuario (Conabio, IMAE, UAA, 2008).

La población total del municipio según el Censo del Instituto Nacional de Estadística y Geografía (INEGI, 2010) es de 54136 personas. La cabecera municipal cuenta con 19742 habitantes y cabe destacar que más de $63 \%$ de la población está distribuida en las distintas comunidades, la mayoría rurales. El municipio, al igual que otros en el estado y la región, está ligado a la migración de la población a Estados Unidos con un índice de migración de 9.86\%, en tanto que $36.16 \%$ de la población económicamente activa se dedica al sector 
primario, $28.17 \%$ al sector secundario y $33.42 \%$ al terciario en el que se incluyen actividades comerciales, turísticas y servicios.

La vocación turística del municipio de Calvillo está vinculada con el turismo de naturaleza, debido a los recursos naturales que posee, como bosques, cascadas (en temporada de lluvias), paisajes, embalses, entre otros. Además, tiene ya una tradición recreativa y de consumo de alimentos en los diversos restaurantes ubicados estratégicamente en las áreas naturales. Aunado a lo anterior, se suman los recursos culturales de la región, como las tradiciones religiosas, entre las que destaca el festejo del Señor del Salitre; las fiestas locales, como la Feria de la Guayaba que se celebra en el mes de diciembre; algunas exhaciendas y la producción de pan, quesos y dulces de guayaba de manera artesanal.

El sector turístico y de servicios del municipio de Calvillo comprende una variedad de empresas, la mayoría en la categoría de microempresas, que van desde la elaboración y venta de productos artesanales como deshilados, pan, dulces de guayaba, venta de alimentos, hasta servicios de hospedaje extrahotelero o especializados, como los spa y expediciones. En el cuadro 1 se muestra el concentrado de dos directorios, el primero corresponde al Consejo Turístico de Calvillo y el segundo al registro del Departamento de Turismo Municipal.

El Consejo Turístico de Calvillo es una organización no gubernamental que está tratando de agrupar incluso a representantes de otras organizaciones, como a los integrantes del mismo Comité Pueblo Mágico Calvillo, la Cámara Nacional de Comercio Delegación Calvillo, la Integradora Turística Explora Calvillo (que incluye ocho empresas lideradas por mujeres), la Asociación de Charros, el Consejo Ciudadano de Cultura, el Comité Sistema Producto Guayaba y el Consejo de Sanidad Vegetal, además de empresas de venta de alimentos y productos artesanales, hospedaje, esparcimiento, etc., con el objetivo de coadyuvar a la gestión turística del destino. Cabe destacar que de sus 58 integrantes, 21 empresas están certificadas con el Distintivo $\mathrm{M}^{2}$ de la Sectur, lo que habla del interés por la mejora continua empresarial. Por otro lado, el Ayuntamiento

2 "El Distintivo M es el reconocimiento que la Secretaría de Turismo otorga a todas las empresas turísticas que han logrado implementar exitosamente el Programa de Calidad Moderniza y que avala la adopción de las mejores prácticas y una distinción de empresa turística modelo". 
Cuadro 1: Concentrado empresarial del sector turístico de Calvillo

\begin{tabular}{llll}
$\begin{array}{l}\text { Directorio } \\
\text { del Consejo Turístico de Calvillo }\end{array}$ & $\begin{array}{l}\text { Núm. de } \\
\text { empresas }\end{array}$ & $\begin{array}{l}\text { Directorio del Depto. } \\
\text { de Turismo Municipal }\end{array}$ & $\begin{array}{c}\text { Núm. de } \\
\text { empresas }\end{array}$ \\
Organizaciones no gubernamentales & 9 & Alimentos & 31 \\
Alimentos & 12 & Hospedaje & 10 \\
Artesanías & 6 & Esparcimiento & 8 \\
Elaboración y venta de productos & 8 & Dulcerías & 7 \\
Esparcimiento & 4 & Agencias de viaje & 5 \\
Hospedaje & 7 & Bares y merenderos & 5 \\
Servicios & 5 & Cafés & 3 \\
Venta de productos & 3 & & \\
\hline
\end{tabular}

* En las nueve organizaciones no gubernamentales están representadas 13 personas. Fuente: Elaboración propia.

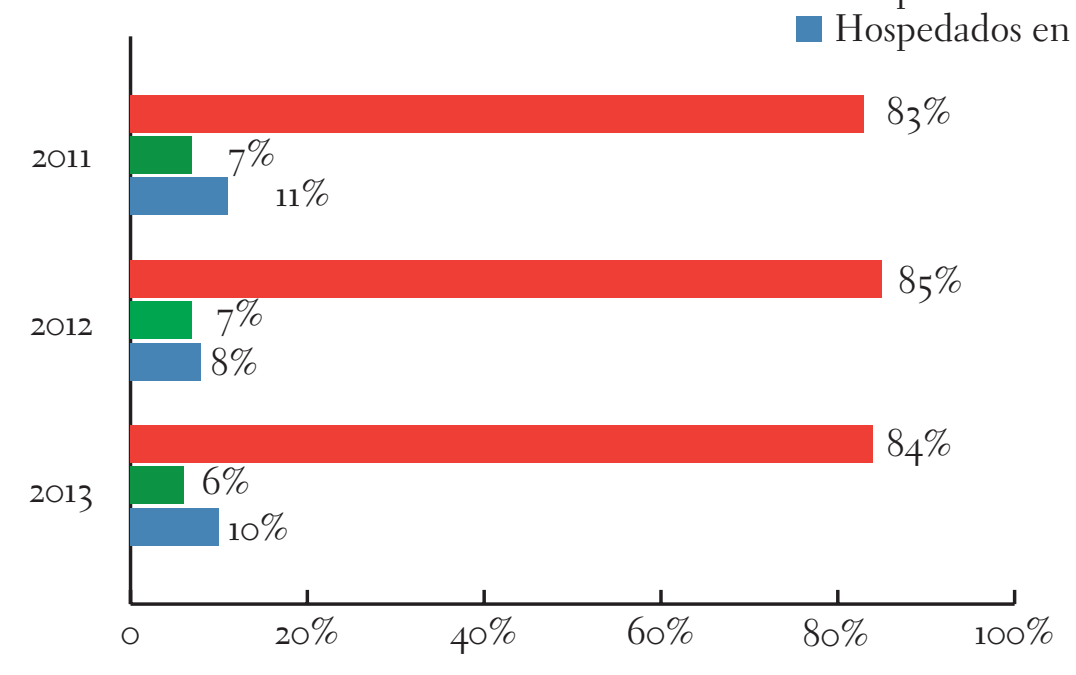

Figura 1. Afluencia anual al municipio de Calvillo 
tiene el registro de 69 establecimientos que directamente se consideran parte del sector turístico, algunos de los cuales también forman parte del Consejo Turístico de Calvillo.

En cuanto a la gestión local gubernamental, desde hace diez años se cuenta con el Departamento de Turismo, adscrito a la Secretaría de Economía del Ayuntamiento, y desde hace tres se agregó una coordinación específicamente dedicada al Programa Pueblos Mágicos y un área para el fomento artesanal. Además de los servidores públicos que dirigen las áreas mencionadas, existen otros que tienen una relación directa o indirecta con la gestión turística municipal, como personal de servicios públicos, finanzas, desarrollo rural, entre otros.

El Departamento de Turismo del Ayuntamiento de Calvillo tiene entre sus funciones llevar un registro de la afluencia de visitantes ${ }^{3}$ al municipio, el cual demuestra claramente en la figura 1 que el destino tiene como principal oferta la venta de alimentos y bebidas en un entorno natural sumamente llamativo. Otras de sus funciones sustantivas es la formación de guías turísticos locales, capacitación para prestadores de servicios, información al visitante y atención de grupos.

\section{Metodología}

El diseño de la investigación es de tipo descriptivo con un enfoque cualitativo y transeccional, lo anterior debido que tiene como "objetivo [...] ubicar, categorizar y proporcionar una visión de una comunidad, un evento, un contexto, un fenómeno o una situación” (Hernández Sampieri, Fernández Collado y Baptista Lucio, 2003, p. 273) en un solo momento. Sin embargo, no se descarta que la investigación mude a un estudio longitudinal para poder analizar la dinámica relacional de la gestión turística conforme avanza el tiempo y se busca la permanencia como pueblo mágico.

El primer paso en el proceso metodológico implementado consistió en la revisión de la literatura especializada sobre análisis de redes y teoría de las partes interesadas con aplicación en la gestión turística. A partir de ello se determinó

${ }^{3}$ El registro de afluencia de visitantes no ha sido consistente en periodos anteriores, por ello sólo se presentan dos periodos completos y uno parcial. 
que sólo se evaluarían las características más sobresalientes de una red, las cuales se definen en el cuadro 2.

\section{Cuadro 2. Definición de variables}

\begin{tabular}{|c|c|}
\hline Variable & Definición \\
\hline Densidad & $\begin{array}{l}\text { Mide la proporción de relaciones existentes sobre } \\
\text { el total de relaciones posibles. Indica la intensidad } \\
\text { de las relaciones en el conjunto de la red. }\end{array}$ \\
\hline Distancia & Indica el esfuerzo para que un actor alcance a otro. \\
\hline Alcanzabilidad & $\begin{array}{l}\text { Un actor es alcanzable por otro si existe un } \\
\text { conjunto de conexiones que van de uno a otro. }\end{array}$ \\
\hline Centralidad & $\begin{array}{l}\text { Estudia a los actores más centrales, más } \\
\text { prominentes, más prestigiosos y poderosos. Para el } \\
\text { caso de redes asimétricas se utilizan los siguientes } \\
\text { indicadores: }\end{array}$ \\
\hline Outdegree & $\begin{array}{l}\text { Indica el número de conexiones/relaciones } \\
\text { directas iniciadas por cada actor. }\end{array}$ \\
\hline Indegree & $\begin{array}{l}\text { Indica el número de actores que se relacionan en } \\
\text { forma directa a cada actor. }\end{array}$ \\
\hline Cercanía & $\begin{array}{l}\text { Mide la distancia media de cada actor con } \\
\text { respecto al resto de los actores de la red. }\end{array}$ \\
\hline Intermediación & $\begin{array}{l}\text { Para cada actor nos indica en qué medida está en } \\
\text { una posición intermediara en las comunicaciones } \\
\text { geodésicas entre el resto de actores. }\end{array}$ \\
\hline
\end{tabular}

Fuente: (Rodríguez \& Mérida, 2006).

Como segundo paso, se seleccionaron a los informantes clave del municipio de Calvillo, uno relacionado con el sector empresarial y otro con la gestión gubernamental local. Se realizaron entrevistas informales con cada uno para obtener 
un universo de actores que tenían como característica estar relacionados con la actividad turística en el destino, tanto en organizaciones gubernamentales como en no gubernamentales. Este ejercicio arrojó un total de 26 personas que pertenecen tanto al ayuntamiento en funciones como al Consejo Turístico de Calvillo. Estos sujetos fueron seleccionados para que se les aplicara un instrumento, por lo tanto, la muestra fue no probabilística con fundamento en el diseño de la propia investigación y en la delimitación de la red, con una perspectiva nominalista al solicitar actores involucrados en la gestión turística de la localidad y afiliados a alguna organización formal.

El instrumento seleccionado fue un cuestionario que contaba con tres secciones: la primera tenía como objetivo conocer algunas características del entrevistado, como género, edad, nivel educativo, ocupación y afiliación. La segunda y tercera recogían información referente a las relaciones que el entrevistado tenía con personas de su propia institución y fuera de ella, en función de la gestión turística, el objetivo de dicha relación, la intensidad de la relación así como una evaluación de la influencia que los actores mencionados tenían en la actividad turística. El tipo de preguntas se consideraron abiertas ya que no se les mostraba ninguna lista previa, pero sólo se les pedía que nombraran a cinco personas, por lo que el límite de la red estaba fijada por los investigadores, técnicas totalmente válidas según Rodríguez (2005).

Para analizar los datos obtenidos, éstos se vaciaron a una hoja de cálculo del programa Microsoft Excel, se procesaron en tablas dinámicas y se integraron matrices adyacentes ${ }^{4}$ con datos binarios que luego fueron exportadas al software especializado Ucinet 6 para generar los estadísticos correspondientes de la red asimétrica ${ }^{5}$, por último se utilizó NetDraw 9.091 para crear los grafos o sociogramas.

${ }^{4}$ Matriz cuadrada que muestra a los actores tanto en filas como en columnas (Rodríguez J. , 2005).

5 "Reflejan la estructura asimétrica de las relaciones entre actores o filiaciones: el valor de la relación entre A y B no es necesariamente igual al valor de la relación entre B y A" (Rodríguez J. A., 2005, p. 28). 


\section{Resultados}

El análisis de resultados está dividido en tres secciones, la primera corresponde a la descripción de los entrevistados, la segunda al análisis de la dinámica relacional de la gestión turística de Calvillo y la tercera al examen más detallado de algunas partes de la red.

El perfil de los entrevistados está caracterizado por los siguientes aspectos:

- El rango de edad de los entrevistados fluctuó de los 23 a los 59 años. El $42 \%$ representó al grupo de 23 a 35 años, $27 \%$ al grupo de 36 a 49 años y el resto al grupo de los cincuenta.

- El género femenino estuvo representado por 58\% del grupo.

- Respecto al nivel educativo de los encuestados, 50\% cuenta con estudios de nivel superior, $38 \%$ de nivel medio (bachillerato) y el resto no contestó.

- En cuanto a la afiliación, premeditadamente se consideró en el diseño del estudio aplicar el instrumento a los dos grupos más representativos de la localidad relacionados con la gestión turística. Por lo anterior, 38\% de los entrevistados forman parte del personal activo del Ayuntamiento en funciones, es decir, servidores públicos y $62 \%$ al Consejo Turístico de Calvillo, una organización no gubernamental que agrupa a diversos empresarios locales y otras asociaciones.

- En el caso del personal del Ayuntamiento, 60\% de los entrevistados eran funcionarios de primer nivel, $30 \%$ mandos medios y $10 \%$ operativo. En relación con el Consejo Turístico de Calvillo, todos guardan la misma jerarquía como miembros, excepto uno que se presentó como vocero del Consejo.

\section{Dinámica relacional de la gestión turística de Calvillo, Aguascalientes}

Como se mencionó en el apartado metodológico, el análisis relacional se basó en el estudio de dos categorías de actores importantes en la gestión turística de Calvillo, el sector empresarial y el gubernamental, lo que arrojó un total de 


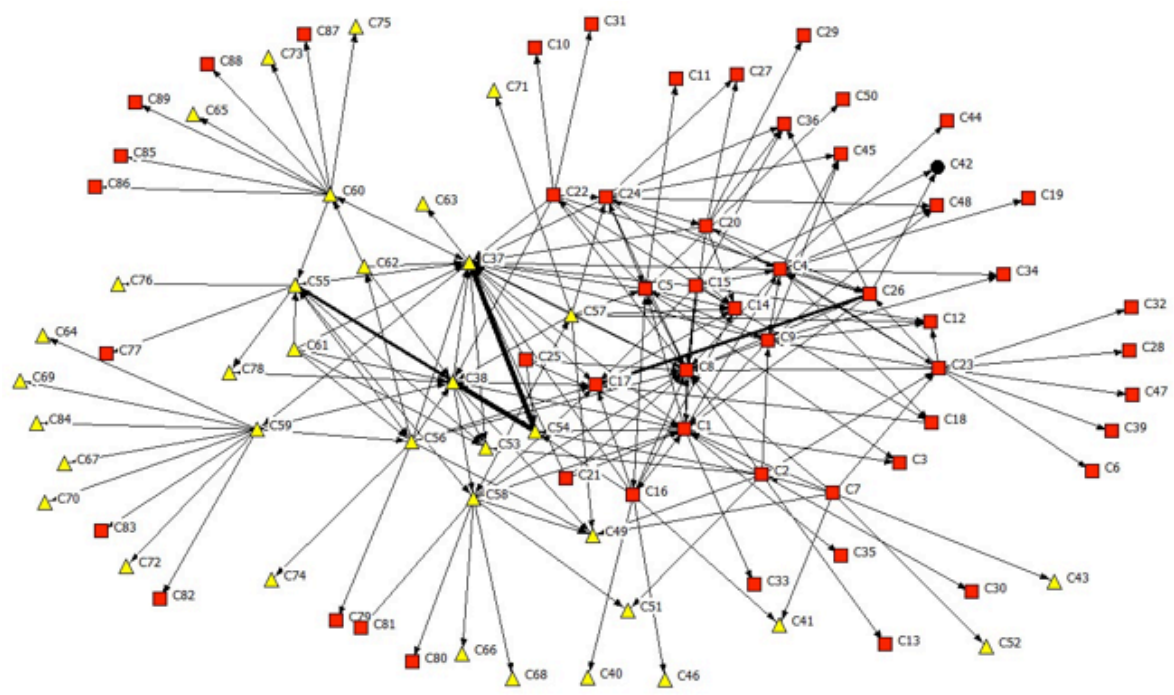

Fuente: Elaboración propia. Representación gráfica obtenida de NetDraw 9.o91.

Figura 2. Dinámica relacional de Calvillo, Aguascalientes.

89 actores citados, que se identifican en la figura 2. Dichos actores son representados a través de nodos que muestran una figura determinada: ${ }^{6}$ los stakeholders de la iniciativa privada están simbolizados con un cuadrado rojo $(60 \%)$ mientras los actores gubernamentales con un triángulo amarillo (39\%), sólo un actor representa a una asociación civil y se ha incorporado con un círculo violeta. También se identifica la intensidad de la relación: cuanto más gruesa es la línea significa una relación mayor.

Según se aprecia, la densidad media de la red es muy baja (2.7\%), lo que indica que hay poca relación entre los diversos actores y además, según se verá más adelante, las relaciones están concentradas por unos cuantos actores que son quienes tienen el control de la red. Además, se destaca el hecho de que son escasas las relaciones bidireccionales, pues principalmente se identificaron vínculos unidireccionales. Otro indicador de la red es el que se refiere a la distancia

${ }^{6}$ En los diferentes grafos que se elaboraron, cada nodo representa un actor y se identifica con un código alfanumérico que se asignó conforme se fueron presentando en las entrevistas (de C1 a C89). 
Cuadro 3. Resultado de las variables del análisis de redes

\begin{tabular}{|c|c|c|c|c|c|}
\hline Variable & $\begin{array}{l}\text { Valores red } \\
\text { completa }\end{array}$ & $\begin{array}{l}\text { Valores } \\
\text { consejo } \\
\text { interno }\end{array}$ & $\begin{array}{l}\text { Valores } \\
\text { consejo } \\
\text { externo }\end{array}$ & $\begin{array}{l}\text { Ayuntamiento } \\
\text { interno }\end{array}$ & $\begin{array}{c}\text { Ayuntamiento } \\
\text { externo }\end{array}$ \\
\hline Densidad & $2.7 \%$ & $1.05 \%$ & $2.2 \%$ & $1.0 \%$ & $2.0 \%$ \\
\hline Distancia & 3.091 & 2.305 & 1.08 & 1.0 & 1.150 \\
\hline Centralidad & 2.4 & 2.615 & 1.148 & 1.231 & 0.867 \\
\hline Outdegree & $2.897 \% *$ & $9.920 \%$ & $7.405 \%$ & $10.180 \%$ & $3.202 \%$ \\
\hline Indegree & $\begin{array}{c}6.345 \% \\
\text { C8-19, C } 37- \\
18, C_{54-12} \\
\mathrm{C}_{17-9}, \mathrm{C}_{1-9}\end{array}$ & $\begin{array}{c}51.520 \% \\
\text { C8-15, C1-8 }\end{array}$ & $\begin{array}{c}20.862 \% \\
C_{37-12}\end{array}$ & $\begin{array}{c}15.582 \% \\
\mathrm{C}_{37-7}\end{array}$ & $\begin{array}{c}5.527 \% \\
\mathrm{C}_{54}-8\end{array}$ \\
\hline Intermediación & $\begin{array}{c}7.66 \% \\
\mathrm{C}_{37}, \mathrm{C}_{1}\end{array}$ & $\begin{array}{c}10.02 \% \\
\mathrm{C}_{1}\end{array}$ & $\begin{array}{c}0.11 \% \\
\mathrm{C}_{9}\end{array}$ & $\begin{array}{c}5.77 \% \\
\mathrm{C}_{37}\end{array}$ & $\begin{array}{c}0.18 \% \\
\mathrm{C}_{5} 6, \mathrm{C}_{3} 8 \\
\end{array}$ \\
\hline
\end{tabular}

*Tómese con reserva pues al aplicar el instrumento se puso límite al número de respuestas.

Fuente: Elaboración propia.

media más corta que existe entre los actores. Para el caso de la red integrada de Calvillo, el valor es de 3.091, lo que significa que cada actor está separado entre sí por otros tres. También se puede observar en la figura 2 que la red tiene numerosos actores que están desvinculados o desconectados y se evidencia un alto índice de relaciones recíprocas.

En el caso de los indicadores de centralidad, el grado de salida (outdegree) de cada actor estaba determinado por el diseño de la investigación al sólo pedirles que mencionaran 10 actores. El grado de salida "refleja la actividad social de cada actor como su capacidad para acceder al resto de los actores” (Rodríguez y Mérida, 2006, p. 13). Sobre este punto destaca que dos actores sólo mencionaron una relación cada uno, $\mathrm{C} 17$ y C18, siendo uno de ellos el que encabeza la coordinación del Comité Pueblos Mágicos.

Por lo que toca al grado de entrada (indegree), a nivel global muestra también un bajo porcentaje, tan sólo de $6.3 \%$. Sin embargo, estos valores cambian y son más altos en el análisis por subgrupos de la red. Los actores más 
prestigiosos para el resto de la red son: el C8 con 19 relaciones, el C37 al cual se identificaron 18 vínculos y el C54 que obtuvo 12. En el caso del análisis interno del Consejo Turístico se reafirma la posición tanto del presidente como del vocero de dicho organismo, como las partes interesadas más prestigiosas o con mayor número de vínculos. Al analizar las relaciones Consejo hacia el exterior, se destaca el actor C37, que con 12 vínculos es la parte interesada reconocida como la más popular. Por lo que toca al estudio interno del Ayuntamiento, se identifica una coincidencia con los resultados obtenidos para el Consejo, pues nuevamente el actor C37 es el que presenta mayor número de menciones, mientras que al exterior del Ayuntamiento destaca el nodo C54 que ostenta ocho vínculos. La media de todas las relaciones de la red es de 2.4 por actor.

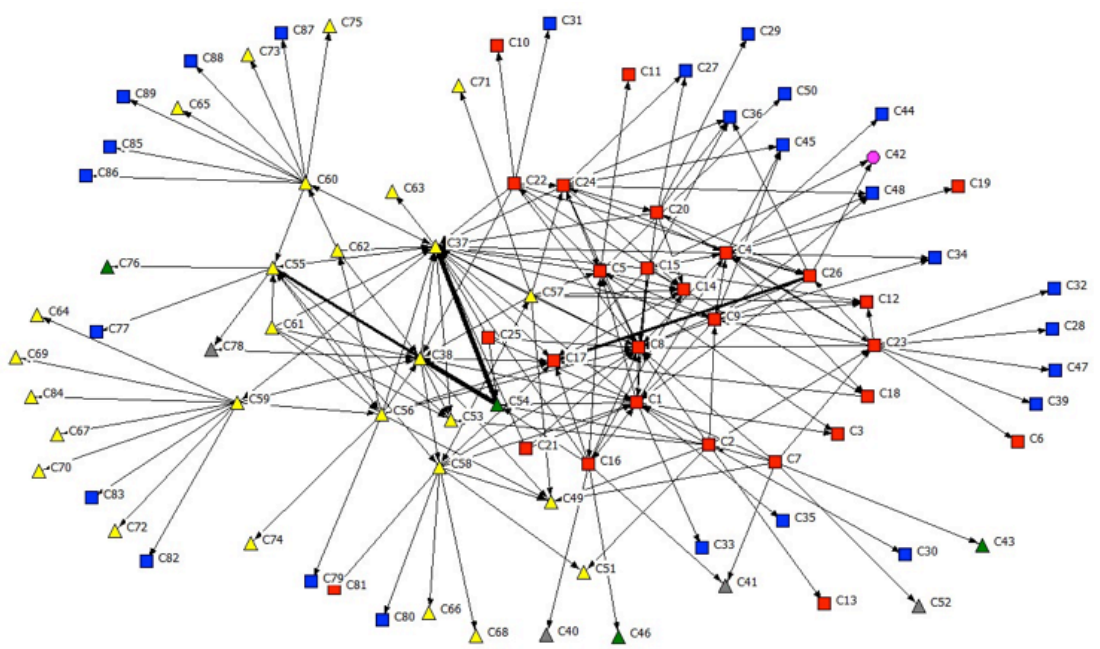

Para este grafo, los cuadros de color rojo representan a los miembros del Consejo Turístico; los cuadros azules a los actores de la iniciativa privada no pertenecientes al Consejo Turístico; los triángulos amarillos al personal del Ayuntamiento; triángulos verdes a dependencias estatales; triángulos grises a dependencias federales; y círculo violeta a una asociación civil.

Fuente: Elaboración propia. Representación gráfica obtenida de NetDraw 9.091

Figura 3. Dinámica relacional de Calvillo, Aguascalientes, mostrando atributos de afiliación. 
Al examinar los datos estadísticos que arroja el software Ucinet 6 sobre las diferentes redes analizadas de la gestión turística de Calvillo, concretamente en lo tocante a los actores puente o intermediarios, se identifican coincidencias en algunos casos respecto a las partes interesadas que tienen mayor grado de entrada. Es así que ubicamos a los actores $\mathrm{C} 37$ y C1 como los nodos con un valor de intermediación más alto, tanto en el análisis de la red global, como en los análisis al interno de los dos organismos analizados. A estos actores se adicionan los nodos C9, C56 y C38 que se destacan en los análisis de las relaciones al exterior de los organismos estudiados (figura 3).

Respecto a la frecuencia de contacto entre los actores, en la red completa se muestran resultados proporcionados de la periodicidad con la que dichos actores dijeron contactarse unos con otros: entre 28 y $29 \%$ (figura 4). Mientras que en el caso del Consejo Turístico y dado que está integrado por diversas empresas, cada una con ocupaciones propias, es lógico que el contacto entre ellos se reduzca en casi la mitad de los casos (41\%) a solamente una vez a la semana, $34 \%$ indica que se realiza dicho contacto sólo una vez al mes, e incluso 15\% menciona que el contacto es esporádico. Este dato también es un indicador de la colaboración que existe respecto a la gestión turística del destino. En el caso de la gestión turística externa del Consejo Turístico, prácticamente la mitad de los actores entrevistados (47\%) expresa una relación esporádica con los demás actores, $25 \%$ dice relacionarse una vez al mes, mientras que $27 \%$ dijo mantener contacto una vez a la semana.

Por su parte, el análisis al interior del Ayuntamiento muestra, como es de esperarse, una mayor frecuencia de contacto diario que asciende a más del cuarenta por ciento de las veces, poco más de $30 \%$ mantienen contacto semanal y sólo $17 \%$ dijeron contactar esporádicamente al actor identificado. Como podría suponerse, esta situación se presenta de manera inversa al preguntar por la frecuencia con que los actores que laboran en el Ayuntamiento mantienen contacto con actores externos vinculados con la gestión turística del destino (figura 4).

En cuanto al objetivo de las relaciones entre el total de los actores, se observa en la figura 5 que en $41 \%$ de los casos se centra en aspectos operativos, mientras que en $35 \%$ de los casos el objetivo tiene que ver con la gestión 


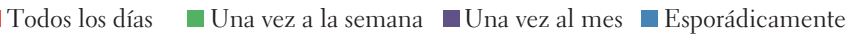

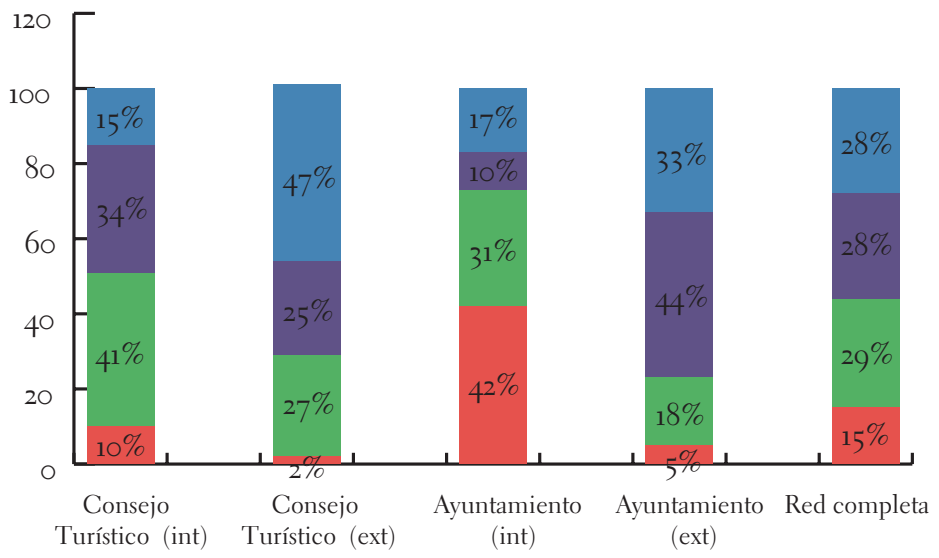

Figura 4. Frecuencia de contacto entre actores

propiamente dicha y sólo $24 \%$ hizo referencia a la comunicación. Por lo que toca al análisis de las relaciones de los integrantes del Ayuntamiento, a nivel interno predomina el objetivo operativo (52\%), seguido de la gestión (38\%) y solo en $10 \%$ se mencionó la comunicación. Y en el caso de las relaciones externas de los servidores del Ayuntamiento, $44 \%$ dijo tener como objetivo en sus vínculos lo operativo, $36 \%$ cuestiones de comunicación, y el restante $21 \%$ temas de gestión.

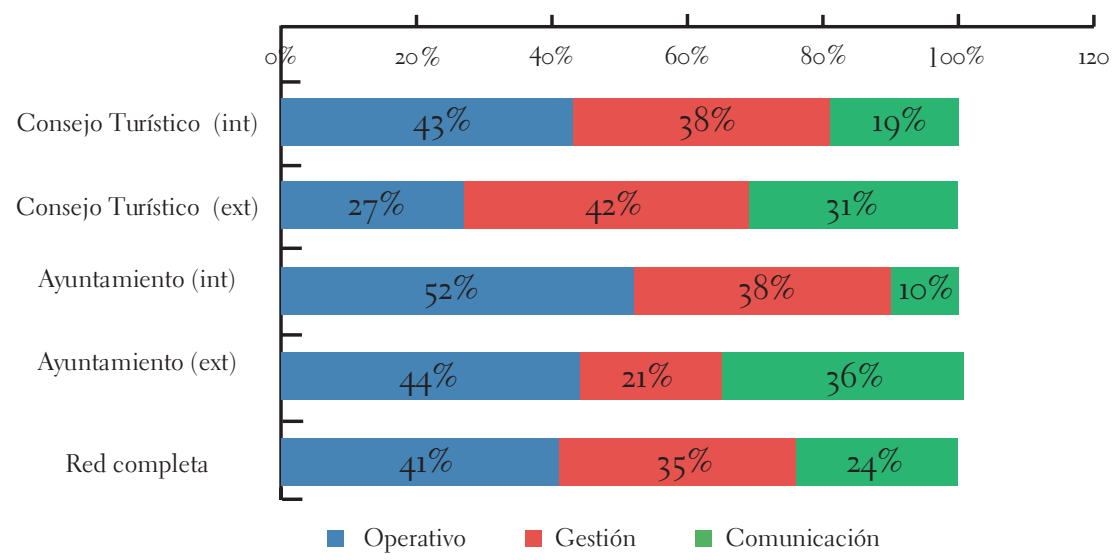

Figura 5. Objetivo de las relaciones entre actores 
Por último, al cuestionar a los miembros del Consejo Turístico de Calvillo el propósito de mantener relaciones con otros actores integrantes del mismo organismo, los aspectos operativos predominaron con $43 \%$, seguido de la gestión (38\%). Mientras que el objetivo principal de las relaciones con actores fuera del Consejo es la gestión (42\%), seguido por la comunicación (31\%) y sólo en $27 \%$ de los casos el objetivo tiene que ver con cuestiones operativas (figura 5).

Al realizar un análisis por separado de la dinámica relacional tanto en el Consejo Turístico como en el Ayuntamiento, desde una perspectiva de sus vínculos internos y hacia el exterior, se obtienen algunos resultados interesantes que permiten complementar la percepción de la gestión turística en el destino.

Iniciando con el análisis relacional al interior del Consejo Turístico (figura 6), se puede observar claramente la fuerte colaboración que existe entre la mayoría de los integrantes del citado organismo y destaca sin duda, el actor C8 quien además de ser el representante, es el actor que cuenta con mayor poder y legitimidad al ser el más reconocido por los integrantes de dicho consejo. Contrastando con esto, puede identificarse la existencia de algunos actores que aun cuando forman parte del Consejo, quedan aislados o no son tan importantes para sus propios compañeros.

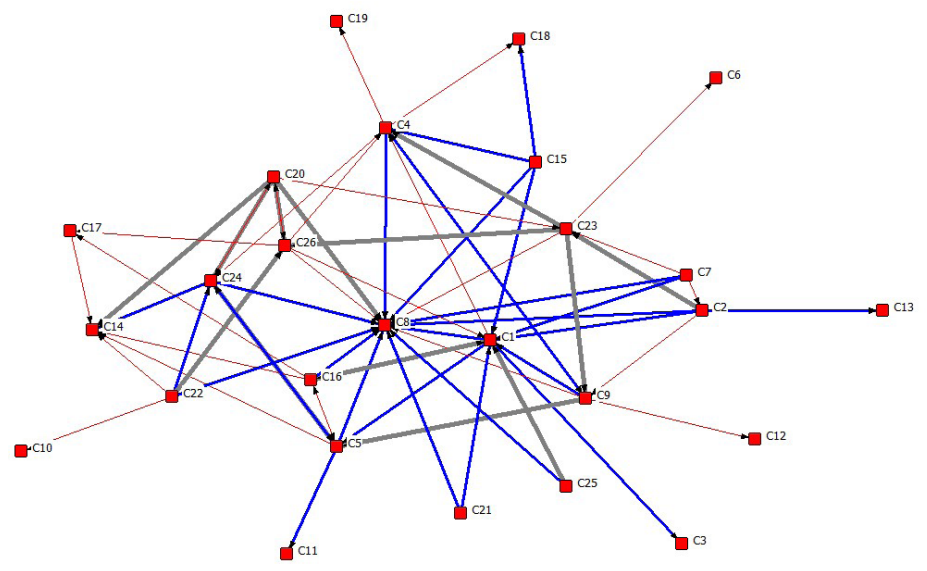

Fuente: Elaboración propia. Representación gráfica obtenida de NetDraw 9.o91

Figura 6. Dinámica relacional del Consejo Turístico de Calvillo internamente. 
Por lo que toca al análisis de las relaciones externas de los integrantes del Consejo Turístico de Calvillo (figura 7), se aprecia una clara vinculación con el Ayuntamiento, en particular con el actor C37, quien es el representante del Departamento de Turismo.

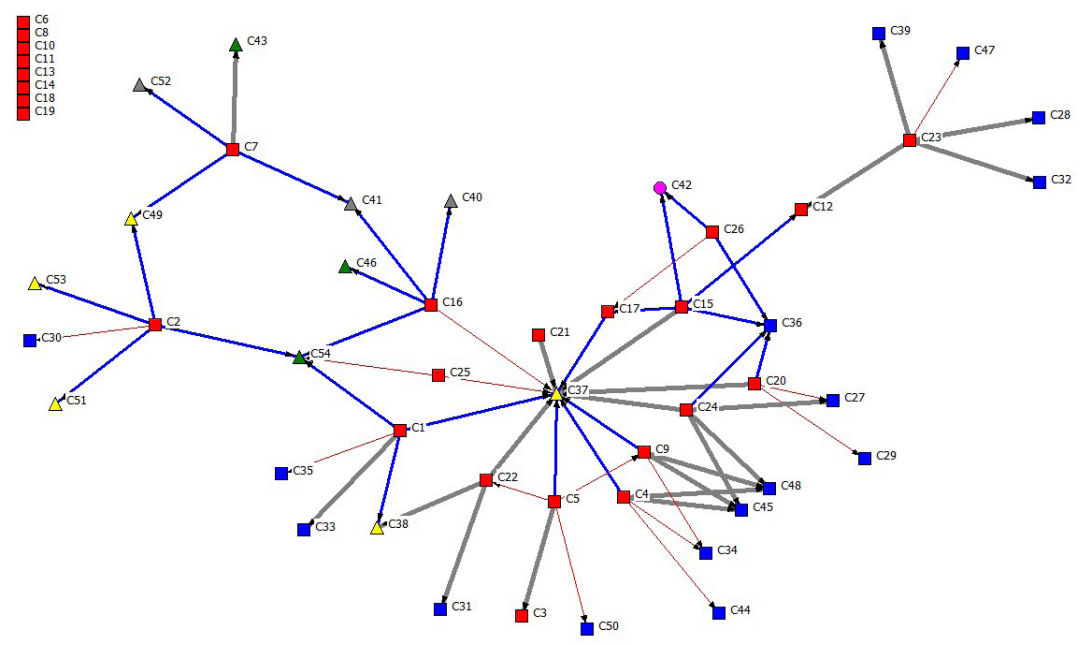

Fuente: Elaboración propia. Representación gráfica obtenida de NetDraw 9.091 Figura 7. Dinámica relacional del Consejo Turístico de Calvillo externamente.

Respecto a la dinámica relacional interna del Ayuntamiento que se presenta en la figura 8, muestra un claro protagonismo por parte del C37 y además destaca el vínculo de éste con el nodo C55, lo cual resulta lógico si se considera a ambos como los entes encargados de la gestión turística gubernamental en el destino. Llama la atención también, la formación de pequeñas subredes que se vinculan con las tareas específicas de cada actor, como es el caso de las relaciones que el nodo C59, que siendo el área de servicios públicos, mantiene un vínculo muy específico con áreas directamente vinculadas con la limpieza y el mantenimiento del destino. 


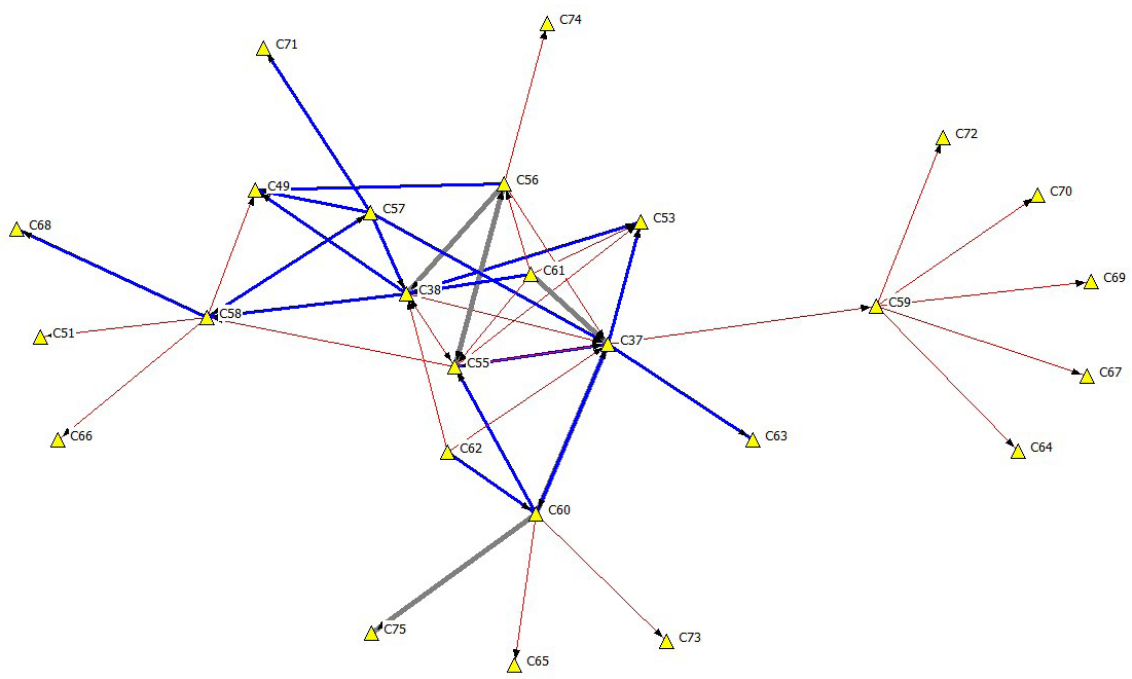

Fuente: Elaboración propia. Representación gráfica obtenida de NetDraw 9.o91

Figura 8. Dinámica relacional del Ayuntamiento internamente
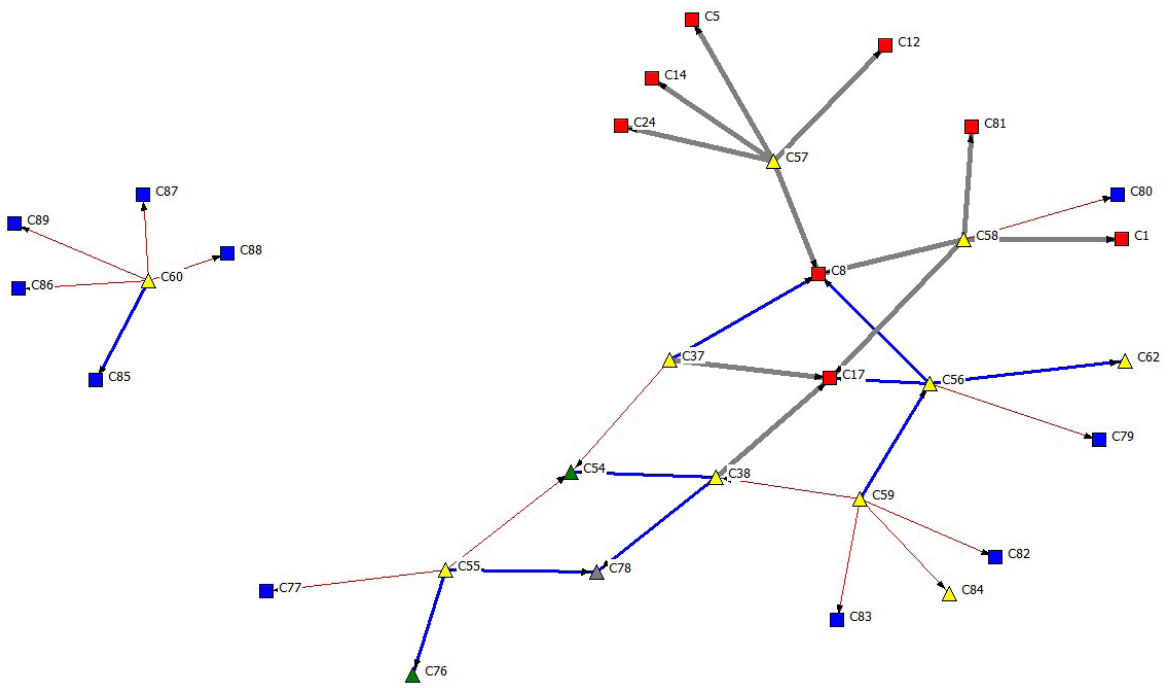

Fuente: Elaboración propia. Representación gráfica obtenida de NetDraw 9.091 Figura 9. Dinámica relacional del Ayuntamiento de Calvillo externamente 
Por último se analizan las relaciones al exterior del Ayuntamiento (figura 9) y se reconocen como actores prestigiosos al nodo C17, presidente del Comité Pueblos Mágicos y al actor C8, presidente del Consejo Turístico. Sin embargo, se denota desarticulación en la red y poca cohesión entre sus integrantes, lo cual da cuenta de la imperante necesidad de fortalecer los vínculos en aras de mejorar la gestión del destino.

\section{Discusión y conclusiones}

La implementación del análisis de redes en este estudio ha permitido identificar a los diversos actores vinculados con la gestión turística de Calvillo, y al complementar el análisis con la identificación de los atributos propuestos por la teoría de las partes interesadas, se obtiene una representación completa sobre la dinámica social vinculada con el turismo que impera en el destino. En este sentido se demuestra la legitimidad de los actores al pertenecer a un grupo organizado que trabaja para el desarrollo turístico local, y también se detectan los actores que cuentan con poder o influencia en la misma gestión.

Retomando el supuesto que se planteó al inicio de este trabajo y que establecía que "las partes interesadas del municipio de Calvillo, en el estado de Aguascalientes, muestran una escasa relación entre ellos para colaborar en la gestión turística de su localidad y ello no se ha mejorado con la incorporación al programa Pueblos Mágicos”, el análisis hasta aquí elaborado proporciona elementos para confirmar dicha sentencia y permite asentar la urgente necesidad de fortalecer los lazos entre los actores, en aras de hacer más eficiente la gestión turística del sitio.

Es claro el liderazgo que en la localidad tienen ciertos actores y ello se corrobora con las medidas de centralidad obtenidas, particularmente el grado de entrada y la intermediación. El primero de ellos posiciona a los actores C8, C37, C54, $\mathrm{C} 17$ y C1, como los nodos principales de la red. Habría que destacar que, como es normal, se trata de las dependencias del ramo a nivel local y estatal y de los representantes de los organismos privados mayormente vinculados con el turismo en el destino como es el Consejo Turístico y el Comité Pueblo Mágico. 
Destacan también, además de los ya citados, los actores C9, C56 y C38 por el grado de intermediación alcanzado. En dos de los casos se trata de dependencias municipales indirectamente relacionadas con el turismo, y el tercero es una agencia operadora de turismo receptivo.

En resumen, se podría establecer que los resultados muestran una red integrada amplia pero poco cohesionada y donde los actores representantes de turismo municipal y estatal así como el Consejo figuran como los que tienen legitimidad y poder. Sin embargo, el presidente del Comité Pueblos Mágicos que debería tener a su cargo la gestión principal sólo tiene legitimidad y urgencia. Ello lleva a reflexionar sobre la importancia de fortalecer las relaciones entre actores pues a pesar de los esfuerzos de asociacionismo no hay colaboración entre el sector público y privado que permita a Calvillo posicionarse como un destino exitoso.

\section{Literatura citada}

La Biodiversidad en Aguascalientes: Estudio de Estado. 2008. México: Comisión Nacional para el Conocimiento y Uso de la Biodiversidad (Conabio), Instituto del Medio Ambiente del Estado de Aguascalientes (IMAE), Universidad Autónoma de Aguascalientes (UAA).

Cruz, J. (noviembre, 2008). Actores y redes de política pública. Su influencia en la orientación turística de Ixtapan de la Sal, México (1930-2005). Toluca, Estado de México.

Cuevas, T. (2007). Gestión-red del desarrollo local. Una aplicación al turismo alternativo en el noroeste de Chihuahua. (Tesis de maestría, Universidad Nacional Autónoma de México).

Freeman, L. C. (2012). El desarrollo del análisis de redes sociales. Un estudio de sociología de la ciencia. Estados Unidos: Palibrio.

Gobierno del Estado de Aguascalientes (2013). Disponible en http://www.aguascalientes.gob.mx

Grimble, R., Chan, M.K., Aglionby, J., y Quan, J. (1995). Trees and trade-offs: A stakeholder approach to natural resource management. Gatekeeper Series 52. Londres: IIED. 
Hernández Sampieri, R., Fernández, C., y Baptista, P. (2003). Metodología de la investigación (Tercera ed.). México, México: McGraw-Hill Interamericana.

Merinero, R. (2009). Desarrollo local y análisis de redes sociales: el valor de las relaciones como factor del desarrollo socioeconómico. REDES. Revista Hispana para el Análisis de Redes Sociales, 18 (11), 277-304.

Merinero, R., y Pulido, J. I. (2009). Desarrollo turístico y dinámica relacional. Metodología de análisis para la gestión activa de destinos turísticos. Cuadernos de Turismo 23, 173-193.

Mitchell, R. K., Agle, B. R., y Wood, D. J. (1997). Toward a theory of a stakeholders identification and salience: defining the principle of who and what really counts. Academy of Management Review , 22 (4), 853-886.

Prell, C., Hubacek, K., y Reed, M. (2007). Stakeholder analysis and social network analysis in natural resource Management. Sri Papers (06), 1-21.

Pulido Fernández, J. I. (2010). Las partes interesadas en la gestión turística de los parques naturales andaluces. Identificación de las interrelaciones e intereses. Revista de Estudios Regionales, 147-175.

Rodríguez, J. A. (2005). Análisis estructural y de redes, 16 (2ª . ed.). Madrid: Centro de Investigaciones Sociológicas.

Rodríguez, J., y Mérida, F. (2006). Ucinet 6.0. Guía práctica de redes sociales. Barcelona: Universitat de Barcelona.

Sectur (2009). Pueblos Mágicos. Reglas de operación. Portal de la Secretaria de Turismo, disponible en http://www.sectur.gob.mx/work/sites/sectur/ resources/LocalContent/15142/20/Reglas_de_operacion.pdf

Vargas, A., y Rodríguez, I. (2012). Análisis de las redes sociales y su aplicación en la gestión turística. Caso Real de Asientos, Aguascalientes, México. En T. Cuevas Contreras y R. Varela Juárez (Eds.), Competitividad, innovación e imaginario en el tejido socioeconómico. Una aproximación teórico-metodológica en turismo. Ciudad Juárez, Chih.: UNAM/UACJUCOL/UABC/UAAS. pp. 177-192. 
Dinámica relacional de la gestión turística en el pueblo mágico de Calvillo, Aguascalientes 